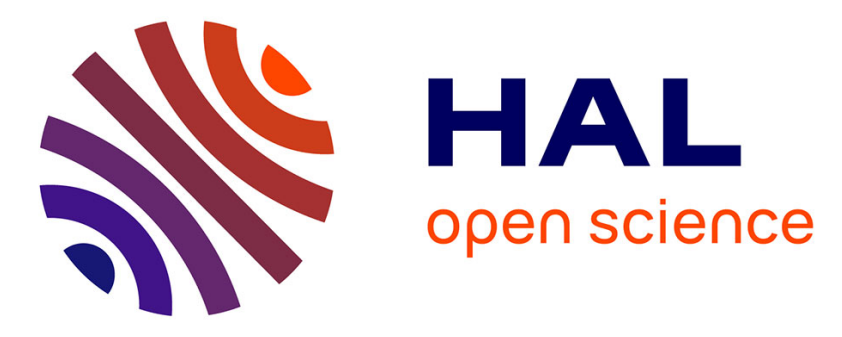

\title{
A New High-Resolution Magnetic Scanner for Sedimentary Sections
}

François Demory, Minoru Uehara, Yoann Quesnel, Pierre Rochette, Carole Romey, Tachikawa Kazuyo, Marta Garcia, Daniel Borschneck, Lucie Pignol, Edouard Bard, et al.

\section{To cite this version:}

François Demory, Minoru Uehara, Yoann Quesnel, Pierre Rochette, Carole Romey, et al.. A New High-Resolution Magnetic Scanner for Sedimentary Sections. Geochemistry, Geophysics, Geosystems, 2019, 20 (7), pp.3186-3200. 10.1029/2019GC008343 . hal-02178640

\section{HAL Id: hal-02178640 https://hal-amu.archives-ouvertes.fr/hal-02178640}

Submitted on 10 Jul 2019

HAL is a multi-disciplinary open access archive for the deposit and dissemination of scientific research documents, whether they are published or not. The documents may come from teaching and research institutions in France or abroad, or from public or private research centers.
L'archive ouverte pluridisciplinaire HAL, est destinée au dépôt et à la diffusion de documents scientifiques de niveau recherche, publiés ou non, émanant des établissements d'enseignement et de recherche français ou étrangers, des laboratoires publics ou privés. 


\section{A New High-Resolution Magnetic Scanner for Sedimentary Sections}

Special Section:

Magnetism in the Geosciences - Advances and Perspectives

Key Points:

- We propose a fast and high-resolution scanning of local magnetic field generated by isothermal remanent magnetization acquired on U-channels

- The scanner offers an optimization of the spatial resolution according to the sedimentary section diameter

- The modeling process is constrained by sedimentary features

Supporting Information:

- Supporting Information S1

- Figure S1

- Figure S2

Correspondence to:

F. Demory,

demory@cerege.fr

Citation:

Demory, F., Uehara, M., Quesnel, Y. Rochette, P., Romey, C., Tachikawa, K., et al (2019). A new high-resolution magnetic scanner for sedimentary sections. Geochemistry, Geophysics, Geosystems, 20. https://doi.org/10.1029/ 2019GC008343

Received 1 APR 2019

Accepted 29 MAY 2019

Accepted article online 18 JUN 2019

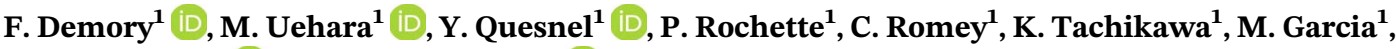 \\ D. Borschneck ${ }^{1}$ iD, L. Pignol ${ }^{1}$, E. Bard ${ }^{1}$ (D), and V. Andrieu-Ponel ${ }^{2}$ \\ ${ }^{1}$ Aix Marseille Université, CNRS, IRD, INRA, Coll France, CEREGE, Aix-en-Provence, France, ${ }^{2}$ Aix Marseille Université, \\ Avignon Université, CNRS, IRD, IMBE, Marseille, France
}

\begin{abstract}
We developed a fully automated magnetic field scanner dedicated to uniaxial magnetic field measurements to determine remanent magnetization intensities and their variations in sedimentary U-channels. A fluxgate magnetometer located as close as possible to the sedimentary section is used to perform uniaxial measurements of magnetic fields generated by the isothermal remanent magnetization of the sediment. This artificial magnetization, which is known to be a powerful proxy in environmental magnetism, is produced perpendicular to the U-channel long axis, and parallel to the fluxgate axis, using a Halbach cylinder prior to the measurement. The present magnetic scanner offers a maximal spatial resolution of $5.8 \mathrm{~mm}$ for point sources. A spatial resolution of $14 \mathrm{~mm}$ is obtained for U-channel samples. The magnetic scanner presents a reliable magnetic field range over about 3 orders of magnitude allowing measurement of magnetizations that saturate the Superconducting Rock Magnetometer in its classical configuration. The estimation of remanent magnetization intensities along the U-channel is based on a modeling approach that uses successive uniformly magnetized prisms. In lacustrine laminated sections, comparison between modeling results based on prisms of a constant thickness, on prisms determined from sedimentary facies, and on prisms determined from X-ray fluorescence data helps to understand the detrital versus diagenetic history of the sedimentary succession.
\end{abstract}

\section{Introduction}

Most of the rock magnetic and paleomagnetic investigations are nowadays performed using Superconducting Rock Magnetometers (SRM). Despite their ability to detect magnetic moments below $10^{-11} \mathrm{Am}^{2}$, superconducting probes saturate above $5 \times 10^{-5} \mathrm{Am}^{2}$ (Figure 1, left) in their classical configuration, that is, for pass-through SRM with an inner diameter of $40 \mathrm{~mm}$. In addition, those standard pass-through magnetometers, due to the distance (several centimeters) between pickup coils and sample, have a large response function that does not offer an optimal spatial resolution (Figure 1, right). Indeed, the large-volume integration of the signal leads to important convolution when measuring continuous sections. If the saturation problem can be easily overcome on discrete samples using spinner magnetometry, saturation and low spatial resolution are difficult to overcome for continuous measurements. Indeed, the degraded spatial resolution due to the convolution of the signal along the long axis of the measured section is a key problem that has challenged the scientific community for decades (Dadson et al., 1974) and even the most recent and sophisticated deconvolution algorithms (Oda \& Shibuya, 1996; Oda \& Xuan, 2014) and softwares (Xuan \& Oda, 2015) are not able to completely solve the problem. Apart from discretization of continuous sections, a better spatial resolution of measurements decreases the volume integration and consequently minimizes the convolution. In order to offer a complementary measurement tool dedicated to artificially produced high magnetic moments and to optimize spatial resolution, we developed a fully automated scanner equipped with a fluxgate probe located as close as possible to the measured sections (sedimentary U-channels) and perpendicular to their long axis to measure the local magnetic field generated by the magnetized sample. The triple advantage of the fluxgate probe is its large dynamic range (more than 3 orders of magnitude, mainly controlled by the 12-bit A/D converter), the lack of saturation and the vicinity to the sample that optimizes the spatial resolution. Using a simple geometry, we focus on uniaxial measurement of the magnetic field generated by an isothermal remanent magnetization (IRM) acquired along the same direction as the fluxgate axis, that is, parallel to the sedimentary bedding. IRM is a proxy for the concentration of ferromagnetic particles, which is often used to estimate the detrital input and/or diagenetic processes in sediments (Dunlop \& Özdemir, 1997). Measuring this uniaxial signal simplifies the 

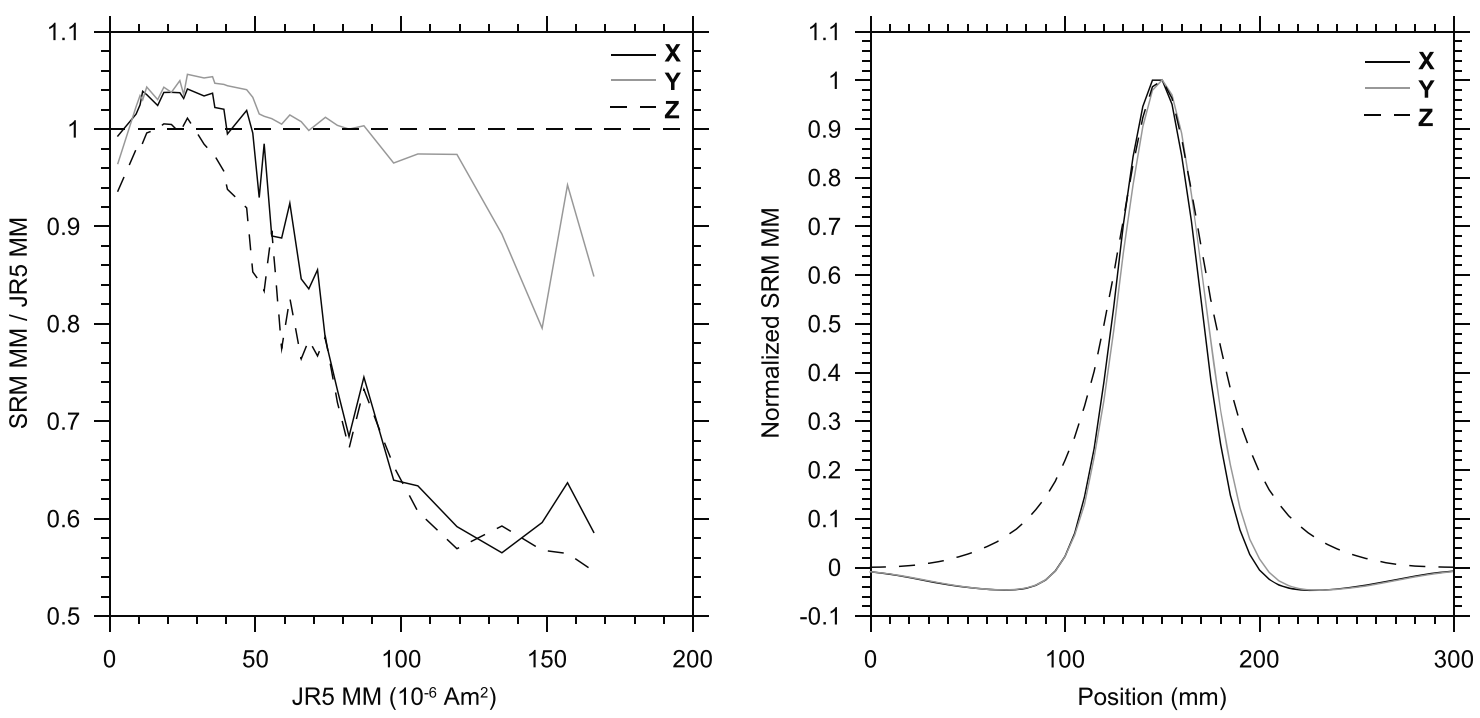

Figure 1. Superconducting Rock Magnetometer performances (model SRM 760R, $2 \mathrm{G}$ enterprises) along its three axes of measurement. (left) Comparison with JR5 spinner magnetometer (AGICO) measurements for high magnetic moments (MM), data below one illustrating the saturation of the SRM. (right) Response functions for each superconducting probes of the SRM: all full widths at half maximum exceed $40 \mathrm{~mm}$.

relationship between the measured magnetic field and sample magnetization. In the case study presented hereafter and led on lacustrine sediments, sedimentological and X-ray fluorescence (XRF) data were used to better constrain the modeling and to evaluate the influence of detrital input and/or authigenesis on magnetic concentration.

\section{Description of the Uniaxial Fluxgate Scanner}

The uniaxial fluxgate probe (model FL1-100, Stefan Mayer Instruments) is placed as close as possible to the U-channel. The fluxgate driving circuit is detached from the sensor head to optimize the mechanical arrangement. The measuring axis is perpendicular to the long axis of the U-channel (Figure 2a) in order to measure the local magnetic field generated by the sediment. To reduce ambient magnetic field variation, the measurement zone is enclosed in a two-layered mu-metal cylinder with inner diameter of $70 \mathrm{~mm}$ and length of $150 \mathrm{~mm}$. The entire equipment is oriented perpendicular to the Earth magnetic field so that the residual magnetic field in the measurement zone without sample is around $200 \mathrm{nT}$. This residual magnetic field is systematically measured and subtracted from the data presented hereafter. The drift can be neglected: it is $\sim 0.35 \mathrm{nT}$ during measurement along $1 \mathrm{~m}$ performed in $\sim 55 \mathrm{~s}$. The noise level within the mu-metal shield during measurement process is $\pm 10 \mathrm{nT}$ (max-min; Figure S1).

The fluxgate sensor was calibrated using Helmholtz coils and a well-calibrated fluxgate sensor from Applied Physics (three-axis fluxgate model 520). It turns out that both probes show a quasi-perfect one to one relationship up to a magnetic field of $35 \mu \mathrm{T}$ (Figure 2b). Above this magnetic field, the relationship is still linear but with a different slope, which can be corrected by a simple calibration function. This correction has not been done since no field values above $35 \mu \mathrm{T}$ are expected for sediments even for those that were artificially magnetized (see section 3.2).

The fluxgate probe is integrated within a duralumin bench sized for 1.5-m-long U-channel (total length $=3.5$ $\mathrm{m})$. The sample is mounted on a $300-\mu \mathrm{m}$-thick plastic tray driven by a stepper motor and a Kevlar wire. A stepper motor ( $\mathrm{M}$ in Figure 2a) moves the sample to the right-hand side of the figure. The left-hand-side limit and the right-hand-side limit of the stage, where the motor stops, are detected by optical sensors at both ends. Since the position of left-hand-side limit has a problem of hysteresis in positioning due to the wire elasticity, we defined a theoretical zero position about $1 \mathrm{~cm}$ right from the left-hand-side limit. This initialization process applies a tension to the wire and reduces the positioning error. To estimate this error, we conducted 10 runs of magnetic field scanning of a small cubic basalt sample $\left(1 \mathrm{~mm}^{3}\right)$ subjected to IRM acquisition parallel to the measurement direction using a field of $3 \mathrm{~T}$ produced by a pulse magnetizer (model MMPM9, 


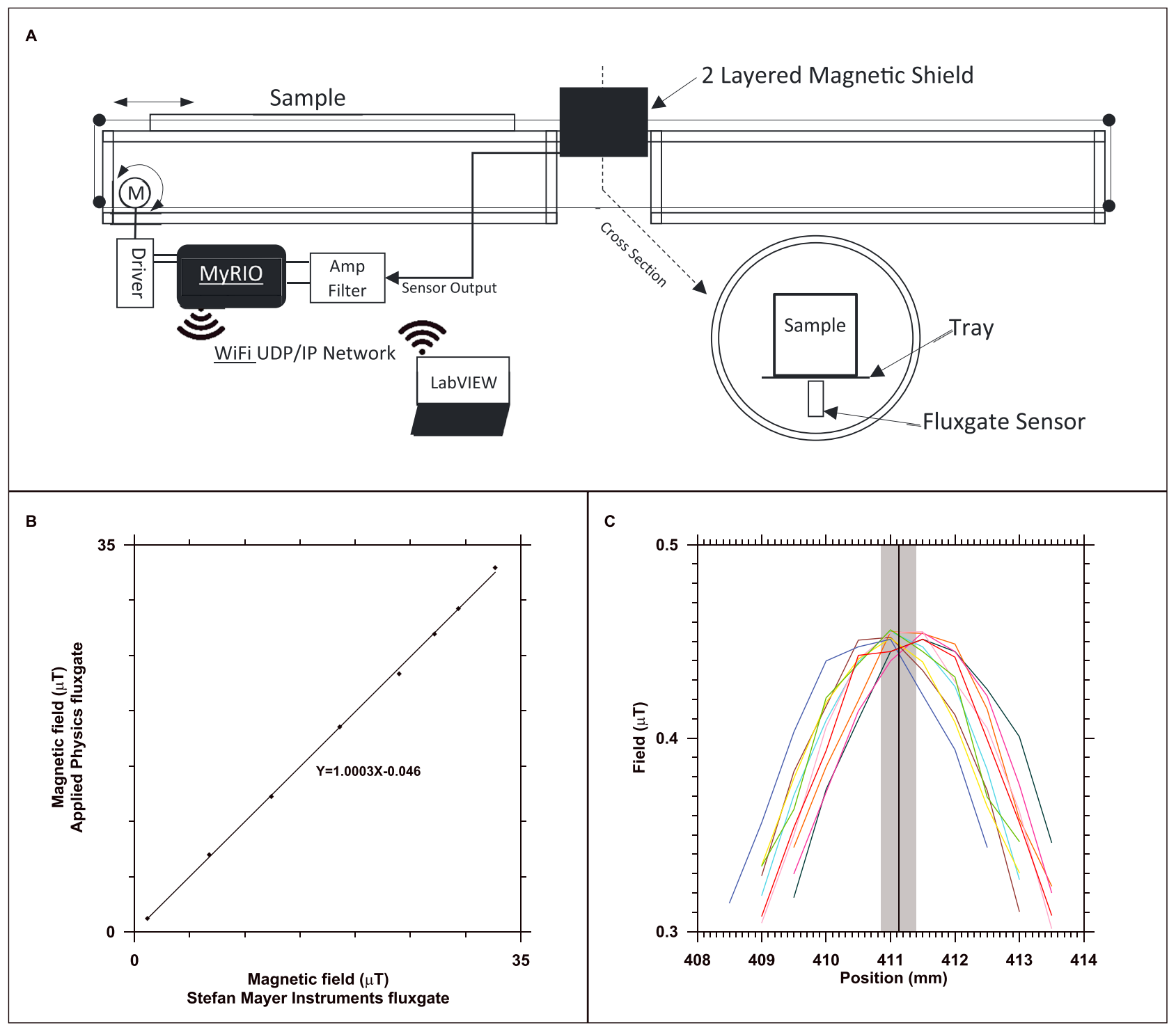

Figure 2. (a) Schematic representation of the scanner: the automated bench is equipped with a fluxgate in close contact with the U-channel and the measurement zone is protected from external magnetic field by a 2two-layered mu-metal shield. The synchronization between movement and measurements is done using MyRio embedded device from National Instruments, and the operating software is built up under LabVIEW. (b) Intercalibration of the fluxgate probe (model FL1-100, Stefan Mayer Instruments) with a well-calibrated fluxgate (3three axes, model 520 from Applied Physics): there is a quasi-perfect 1 to 1 relationship up to $35 \mu$ T. (c) Positioning repeatability test for a cubic sample of basalt of $1 \mathrm{~mm}^{3}$ with 10 runs of fluxgate scanning: the gray area corresponds to the standard deviation of the average sample position.

Magnetic Measurements). The polynomial fits of the 10 runs of scanning (0.5-mm step) show that the absolute positioning error and the standard deviation of the positioning are 0.89 and $0.262 \mathrm{~mm}$, respectively (Figure 2c).

The fitting model is

$$
B_{Z}=k^{*} h /\left(\left(x-x_{0}\right)^{2}+h^{2}\right)^{2}
$$

where $B_{z}$ is the observed magnetic field, $k$ is a constant, $h$ is the height of the sensor, $x$ is the position, and $x_{0}$ is the position of the quasi-point dipole source (1- $\mathrm{mm}^{3}$ cubic basalt sample).

The measurement consisting in the synchronous sample displacement and magnetic field measurement is conducted by an embedded LabVIEW real-time software running on a MyRIO unit with integrated 12-bit 


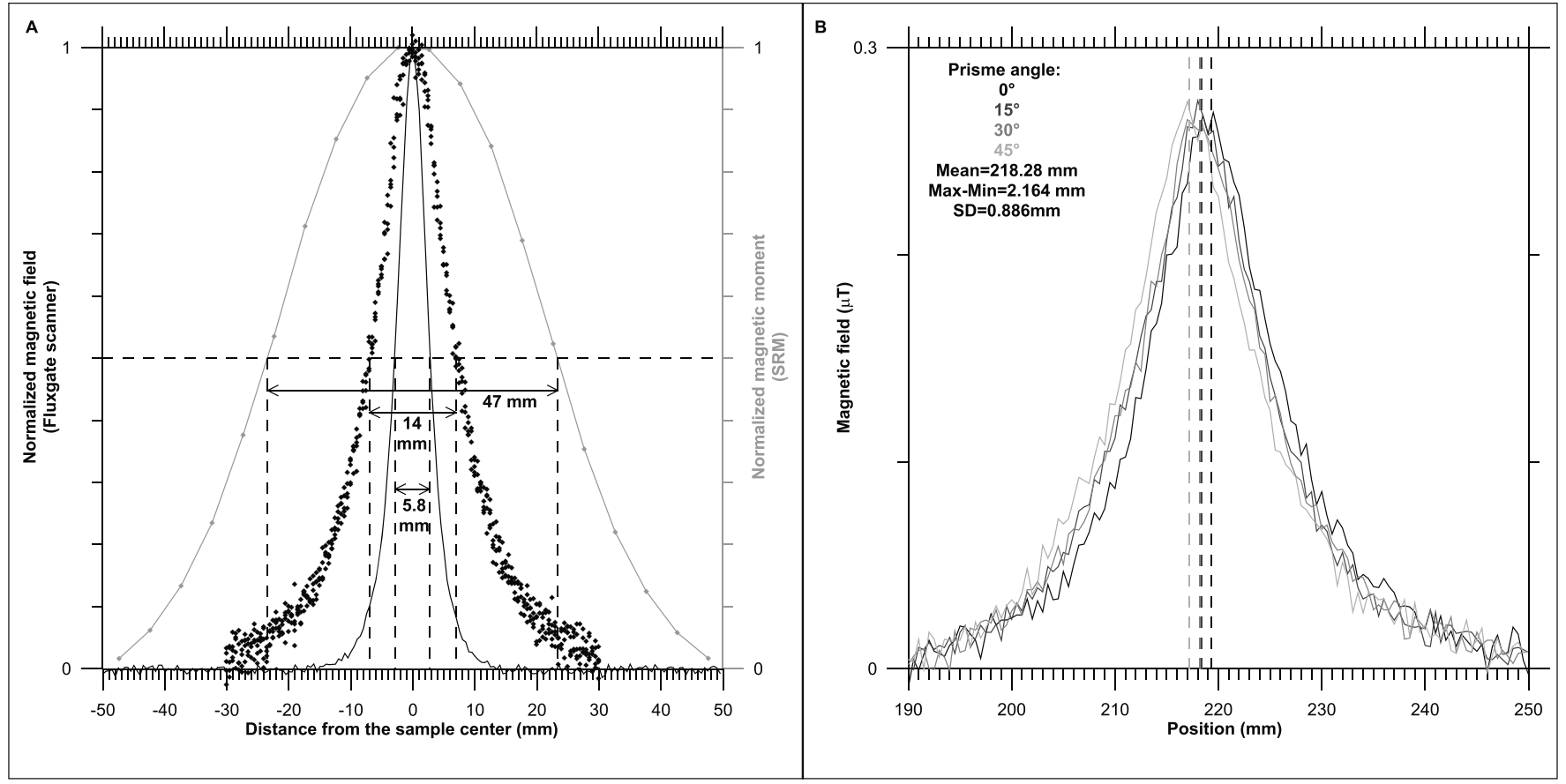

Figure 3. (a) Normalized response functions of the fluxgate and SRM ( $x$ axis) probes. The finest spike (full width at half maximum $=5.8 \mathrm{~mm}$ ) corresponds to the fluxgate scanning of a cubic sample of basalt of $1 \mathrm{~mm}^{3}$. The medium spike (FWHM $=14 \mathrm{~mm}$ ) and the large spike $(\mathrm{FWHM}=47 \mathrm{~mm})$ correspond to the magnetic field from the fluxgate scanning and the magnetic moment measurement with the SRM for the IRM acquired on a $20 \times 20 \times 2.5$-mm prism of a homogeneous ignimbrite included in an empty U-channel, respectively. Note that response function of the ignimbrite prism was built with five runs of measurements. All samples were subject to IRM acquisition parallel to fluxgate and SRM probes prior to measurements. (b) Fluxgate scanning for the ignimbrite slice with different tilts from 0 to $45^{\circ}$ : the dashed lines show the location of the maximum values deduced from a fitting model applied to each response function.

differential A/D converters (National Instruments). The output noise density of the fluxgate is less than 20 $\mathrm{pT} / \mathrm{Hz}^{1 / 2}$ at $1 \mathrm{~Hz}$ according to the supplier data sheet. The first-stage second-order low-pass filter ( $\mathrm{fc}=2.5$ $\mathrm{kHz})$ cuts the excitation signal of the fluxgate sensor itself, which is the main source of the noise. The acquisition system consists of a differential amplifier with first-order low-pass filter (gain $=1, \mathrm{fc}=140$ $\mathrm{Hz}$ ) and the 12-bit A/D converter of the MyRIO unit. The value of the least significant bit of this system is $48.83 \mathrm{nT}$ and the full scale is $\pm 100 \mu \mathrm{T}$. The oversampling method (averaging of 100 samples for 1 measurement) increases theoretically the apparent resolution by a factor of 10 (least significant bit $\approx 5$ nT; Hauser, 1991). This theoretical least significant bit has been confirmed by noise analysis (Figure S1). The scanning is controlled by a LabVIEW software running on a personal computer. A wireless network communication enables the computer to be set up away from the sensor, which reduces electromagnetic interferences from the computer. It also cuts the noise propagating through the communication cables. The scanning speed can be chosen by the user. In all the measurements performed in the present study, the speed of scanning was less than 1 min per meter with measurement every $\sim 500 \mu \mathrm{m}$.

\section{Fluxgate Scanner Performance}

\subsection{Spatial Resolution}

Based on the fluxgate scanning of the millimetric basalt cube done to estimate the positioning error, a spatial resolution of $5.8 \mathrm{~mm}$ is observed (Figure 3a). We consider it as the maximum spatial resolution since the thickness of the measured continuous section will be a parameter affecting this resolution. In order to estimate the spatial resolution in the case of U-channel measurement, we placed a homogeneous ignimbrite prism of $20 \times 20-\mathrm{mm}$ area and 2.5-mm thickness in an empty U-channel. We magnetized the prism in the same way than the basalt. In this configuration the spatial resolution observed is $14 \mathrm{~mm}$. The same prism measured with the Superconducting Rock Magnetometer (model 760R, 2G enterprises, inner diameter 40 $\mathrm{mm}$ ) shows a spatial resolution of $47 \mathrm{~mm}$, that is, 3.5 times lower than the fluxgate scanner (Figure 3a). 

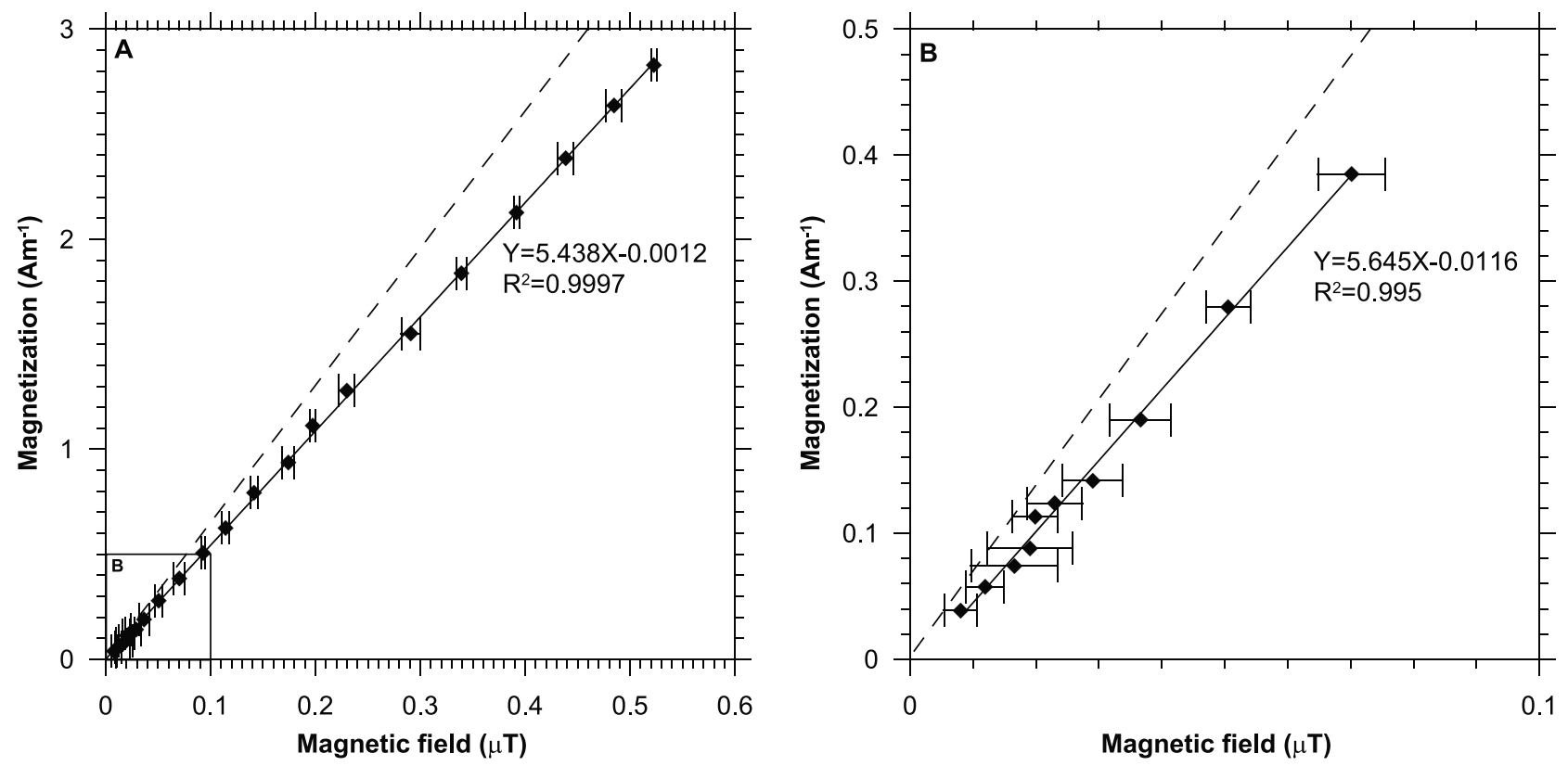

Figure 4. (a) Comparison between magnetization and maximum magnetic field obtained for the magnetic scanning of a cubic sample of $8 \mathrm{~cm}^{3}$ of ignimbrite subjected to stepwise increased uniaxial magnetizations in order to cover the higher part of the dynamics range of the Superconducting Rock Magnetometer and the lower part of the dynamics range of the fluxgate scanner. The standard deviation retrieved from the average of the five highest values of magnetic field is influenced by slight magnetic heterogeneities in the ignimbrite sample. The dashed line illustrates the signal attenuation due to the sample/sensor distance increase when the sample in enclosed in the 2-mm-thick plastic of a U-channel (the magnetic field signal is reduced of $\sim 20 \%$ ). (b) Close-up for the interval 0 to $0.1 \mu \mathrm{T}$.

By this increased resolution, the fluxgate scanner may fill the gap between classical magnetic measurements using pass-through Superconducting Rock Magnetometer and submillimeter-scale magnetic measurements of thin sections using Superconducting QUantum Interference Device (Weiss et al., 2007), MagnetoImpedance (Uehara \& Nakamura 2007), Giant Magneto-Resistance (Hankard et al., 2009), or using Magneto-Optical-Imaging (Uehara et al., 2010), Hall Probe Microscopy (Shaw et al., 2016), Magnetic Tunnel Junction Microscopy (Lima et al., 2014), or Quantum Diamond Microscopy (Glenn et al., 2017). The spatial resolution made possible by the optimized geometry of the fluxgate scanner is close to the spatial resolution of others proxies acquired on continuous sections like, for example, XRF measurements (e.g., Rothwell \& Croudace, 2015).

Magnetic anisotropy could generate an angle between the magnetizing field and the sample magnetization, thus biasing our scheme for relating the magnetization and the measured field. However, as magnetizing field is along the bedding, that is, usually the plane of easy magnetization, we do not expect serious anisotropy bias. Another directional problem could be the occurrence of a dip of the sediment in the U-channel. We quantified the effect of such dip on the signal position and intensity. For that, we tilted the ignimbrite prism enclosed in a U-channel by increasing angles then magnetized it perpendicular to the U-channel long axis and performed scanning after each tilting step. It turns out that even with a dip of $45^{\circ}$, there are almost no changes in field intensity while the maximum signal location moves by only a few millimeters (Figure 3b). Maximum locations were deduced using the same fitting model used for Figure 2c, $x_{0}$ being the position of the base of the prism.

\subsection{Dynamic Range of Measurements}

In order to estimate the dynamic range that can be measured by the fluxgate scanner, we compared magnetic field measured with the fluxgate scanner and magnetization measured with SRM for a cubic sample of homogeneous ignimbrite of $8 \mathrm{~cm}^{3}$ (Figure 4). This comparison is done in the dynamic range in which the superconducting sensors (used to measure the magnetization in this calibration step) are not saturated. To achieve this condition, the ignimbrite sample was subjected first to anhysteretic remanent magnetization acquisition with stepwise increase of the bias DC field up to $400 \mu \mathrm{T}$ (AC field of $100 \mathrm{mT}$ ) and second to stepwise acquisition of isothermal remanent magnetization up to $160 \mathrm{mT}$ with the pulse magnetizer. By 
comparing the two types of measurements we obtain a quasi-perfect linear correlation $\left(R^{2}-1=3 \times 10^{-4}\right)$ between magnetic field (measured by our fluxgate sensor) and magnetization (deduced from the superconducting sensors; Figure 4). The error bars on Figure 4 correspond to the standard deviation calculated from the average of the five neighbor magnetic field values measured around the center of the sample. Considering a measurement step of $\sim 500 \mu \mathrm{m}$, it corresponds to an interval of $2.5 \mathrm{~mm}$, far below the size of the ignimbrite sample, avoiding border effects on average calculation. Standard deviations are attributed to slight heterogeneities in the ignimbrite sample and in a lesser extent to the noise level. Considering a noise level of $\pm 10 \mathrm{nT}$ (max-min) and the relationship between magnetic field and magnetization ( $20 \mathrm{nT}$ for 0.1 Am; Figure 4, right), we may consider a detection limit of $0.05 \mathrm{Am}$ for $8 \mathrm{~cm}^{3}$, that is, on the order of $4 \times$ $10^{-6} \mathrm{Am}^{2}$, as a reasonable estimate for the fluxgate scanner. This detection limit can be decreased by stacking, taking advantage of the low time consumption of the scanning procedure. It must also be noted that the detection limit is a little bit higher considering an increased distance of $2 \mathrm{~mm}$ between sample and sensor when the sample is enclosed in a U-channel. Indeed, the thickness of the U-channel wall reduced the signal of about 20\% (dashed line in Figure 4). Concerning the upper limit of measurements, an extrapolation of the linear relationship between field and magnetization indicates that the fluxgate linearity limit of $35 \mu \mathrm{T}$ corresponds to U-channel with magnetizations of more than 200 Am (Figures 3a and 4a). For higher magnetizations, the fluxgate used in the present study would need a calibration correction.

\section{Modeling Approach: From Magnetic Field to Magnetization and Estimation of the Distance Between Probe and Sample Base}

The uniaxial magnetization intensity variations can be derived from the magnetic field measurements by discretizing the U-channel sample in a series of uniformly magnetized prisms.

The used formula for a single measurement along the core section (whatever its position with regards to the prisms) is

$$
B_{x}=\sum_{i}^{n} M_{x}^{i} V^{i}
$$

where $B_{x}$ is the uniaxial (along $x$ ) magnetic field intensity measurement in tesla, $M_{x}^{i}$ is the uniaxial magnetization intensity of the $i$ th prism in Am, and $V^{i}$ is the system of volume integrals (in cubic meters expressed along $x$ ) which relies the measurement position to the edges and corners of the $i$ th prism (see in Plouff, 1976, equation 17).

Since the uniaxial magnetization intensity is the only unknown parameter for each prism, the resulting magnetization distribution can be computed by inversion of the data series using a classical least squares technique with bounds on the $M_{x}^{i}$ variables $\left(10^{-14}<M_{x}^{i}<10^{5} \mathrm{Am}\right.$; see Quesnel et al., 2008, and references therein for a discussion on standard deviation values of the unknowns). It locally minimizes a cost function using a robust conjugate gradient method (Trust Region Reflective algorithm described in Branch et al. (1999)) suitable for large sparse problems. This is a standard SciPy function in Python language that allows solving optimization problems. However, a calibration is needed to validate the modeling method with the used system. A first step consists in the investigation of the exact distance between the center of the fluxgate sensor and the base of the sample (called height hereafter). To determine this parameter, we used the data obtained from fluxgate scanning and magnetic moment measurement (using SRM) of the IRM acquired on the homogeneous ignimbrite prism of $20 \times 20$ - $\mathrm{mm}$ area and $2.5-\mathrm{mm}$ thickness in an empty U-channel presented in Figure 3a. From modeling, it turns out that the magnetization of $9.73 \mathrm{Am}$ - value given by the SRM for calibration - is obtained for a distance between sample base and maximum signal probe at of $10.6 \mathrm{~mm}$ (Figure 5a). The height is also characterized by a minimum in the root square residual. A change of \pm 1 $\mathrm{mm}$ of this height does not strongly affect the shape of the modeled response function with a difference for the maximum value not exceeding $10 \%$ (Figure $5 \mathrm{~b}$ ). The misfit between model and data on both tails of the curve are attributed to interactions between the magnetic field lines and the shield. The estimated height is slightly lower than expected by the geometry of the device considering the fluxgate casing size $(20 \mathrm{~mm})$, the tray thickness $(0.3 \mathrm{~mm})$, and the U-channel plastic thickness $(2 \mathrm{~mm})$. It seems therefore that the maximum signal is not located in the center of the fluxgate probe casing.

The pertinence of the modeling approach was then tested using a real case study. 


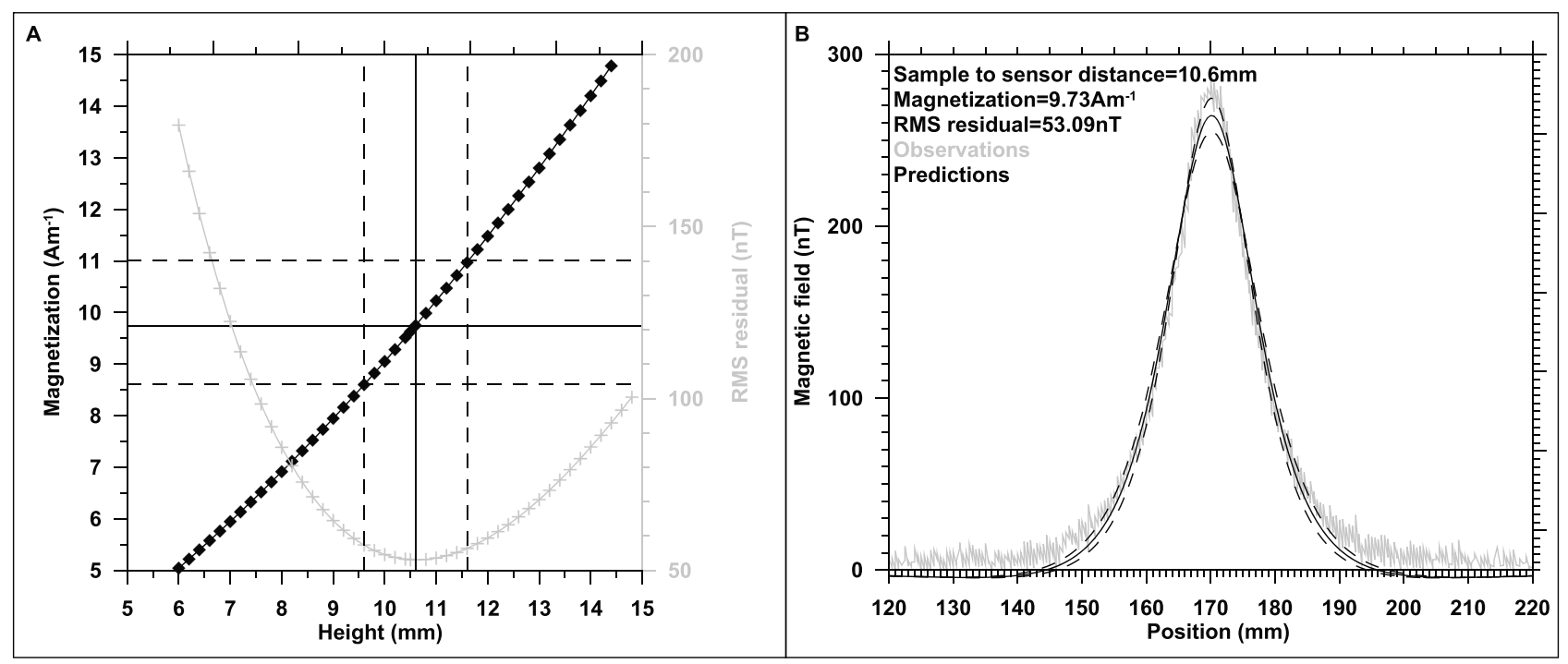

Figure 5. (a) Results of the magnetic field modeling in terms of magnetization and root-mean-square residuals for various heights (distance between sample base and the fluxgate probe). (b) Stacked magnetic field scanning of the $20 \times 20 \times 2.5$-mm ignimbrite slice in an empty U-channel and resulting modeling for predicted magnetization equivalent to the magnetization measured with the SRM. The optimal calculated distance between maximum signal within the fluxgate probe and sample base is $10.6 \mathrm{~mm}$ in order to fit the SRM calibration. The dashed lines correspond to the magnetic modeling with a distance probe/sample of $\pm 1 \mathrm{~mm}$. Note that the best fit for the topmost part of the response function corresponds to the lowest probe to sample distance.

\section{Case Study: The Cassis Paleolake Sediments}

The studied paleolake (Romey et al., 2014), with a dimension of approximately $500 \mathrm{~m}$, is located in a small alluvial plain at $86-\mathrm{m}$ altitude, $2 \mathrm{~km}$ from the Mediterranean Sea in Cassis (southeastern France; $43^{\circ} 13^{\prime} 33^{\prime \prime}$ $\mathrm{N}, 5^{\circ} 32^{\prime} 32^{\prime \prime} \mathrm{E}$ ). From these lacustrine marls, a 50-m-long sedimentary core was retrieved using a SEDIDRILL 250-90 drill (CEREGE, C2FN-INSU).

\subsection{Sediment Description}

A high-frequency layering characterizes the sedimentary sequence with textural and color variations (Figure 6). Peak Counter software (Marshall et al., 2012) was used for laminations counting from 11- to 50-m depth (under the oxidized zone) according to color and texture variations. In this depth interval, 4,250 layers were identified. This succession is an alternation of clayey and sandy layers from $1 \mathrm{~mm}$ to 50 $\mathrm{cm}$ thick. Overprinting this granulometric contrast, gray color variations from light gray to dark gray are also observed, sediments rich in organic carbon and/or sulfides being darker. Clayey laminations and dark gray layers indicate a quiet depositional process probably occurring in deep and anoxic depositional environment, whereas sandy levels are probably linked to hydrodynamic pulses (Romey et al., 2014). Beyond paleoenvironmental implications, this high-frequency variation in sedimentary properties makes the sequence particularly attractive to test our high spatial resolution magnetic scanner.

\subsection{Magnetic Mineralogy}

Nine discrete cubic samples were extracted from various lithologies in order to characterize the magnetic mineralogy. Saturation Isothermal Remanent Magnetization (SIRM) was acquired at $3 \mathrm{~T}$ using a pulse magnetizer MMPM9 (Magnetic Measurements Ltd.) and measured with the SRM 760R (2G Enterprises). The thermal demagnetization of SIRM was performed with 12 temperature steps from room temperature to $630{ }^{\circ} \mathrm{C}$. Hysteresis loop and back field curves were obtained from the same lithologies using a Vibrating Sample Magnetometer MicroMag 3900 (Lakeshore).

Thermal demagnetization of SIRM, successfully performed for seven among the nine samples (two samples were damaged during heating procedure), provides a main unblocking temperature around $350{ }^{\circ} \mathrm{C}$ and a secondary one near $600{ }^{\circ} \mathrm{C}$ (Figure 7a). Most samples have lost their initial SIRM at $350{ }^{\circ} \mathrm{C}$ with a strong decrease of the intensity between $250{ }^{\circ} \mathrm{C}$ and $350{ }^{\circ} \mathrm{C}$. This maximum unblocking temperature may indicate either greigite, pyrrhotite, or maghemite (Chang et al., 2008; Roberts, 1995; Roberts et al., 2011). However, 


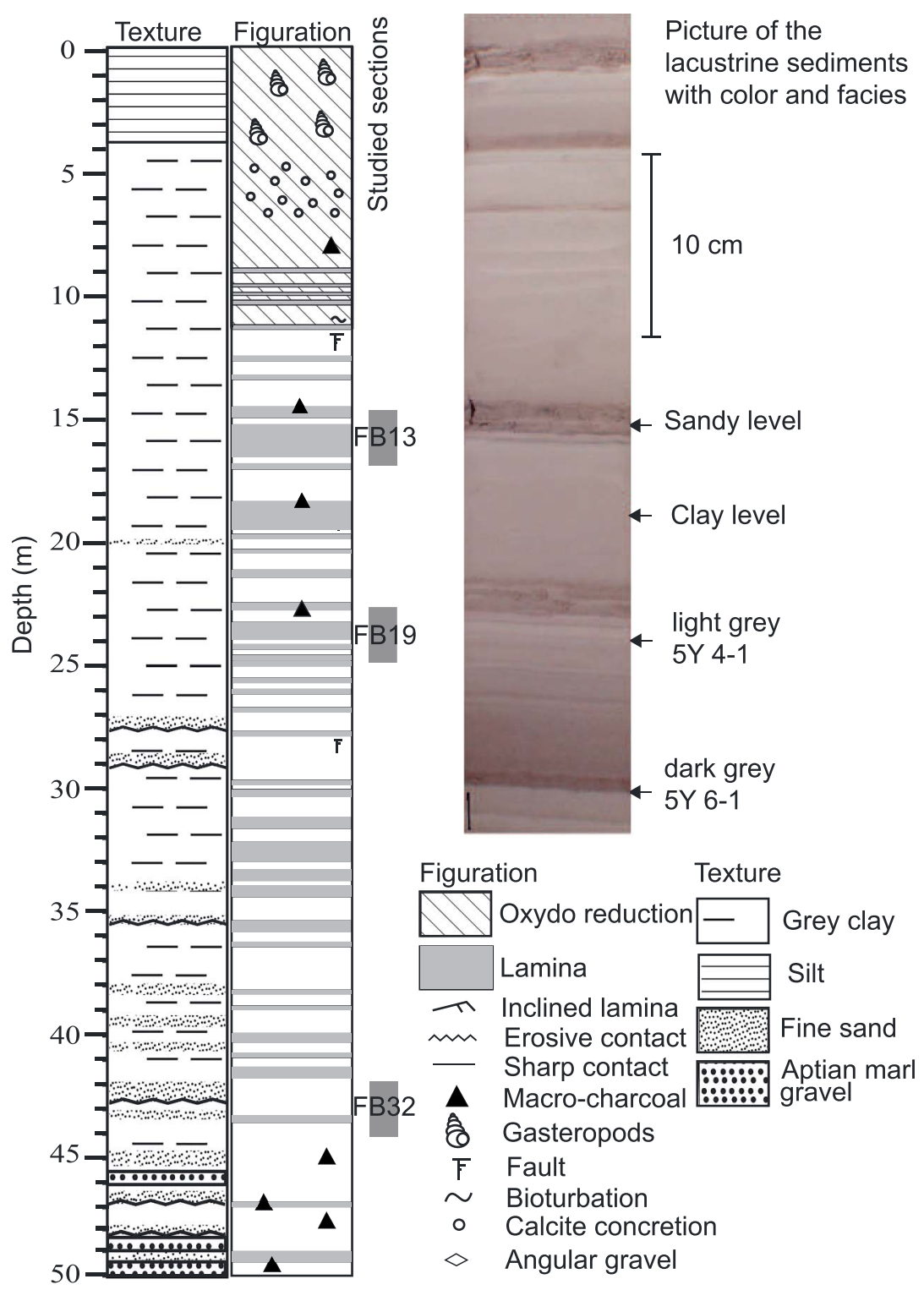

Figure 6. Schematic sedimentary log of Cassis paleolake. A right-color photography of sediment is shown with color indication (Mussel code). The paleoenvironmental interpretation in the present study only concerns the nonoxidized sediments. The location of the three studied U-channels in the sedimentary sequence is also indicated.

maghemite is excluded by the reduced state of the sediment, and greigite rather than pyrrhotite is the magnetic iron sulfide often described in lacustrine sediments affected by reduction processes (e.g., Demory et al., 2005). For samples FB19 and FB28, 4 and $11.4 \%$ of the initial SIRM signal remain at $350{ }^{\circ} \mathrm{C}$ and less than $0.3 \%$ remain above $600{ }^{\circ} \mathrm{C}$. This maximum unblocking temperature below $600{ }^{\circ} \mathrm{C}$ is attributed to magnetite, stable in suboxic conditions.

Magnetite and greigite are also confirmed by hysteresis measurements, which show single-domain and pseudo-single-domain characteristics for samples rich in greigite and magnetite, respectively (Figure 7b). Hysteresis and backfield parameters display mostly high values of $M_{r} / M_{\mathrm{rs}}$ and low values of $B_{\mathrm{cr}} / B_{c}$ close to the SD/PSD limit (Figure 7c). Samples located in the PSD and MD zones are characterized by low magnetization, this latter being carried by magnetite of variable grain sizes.

$\mathrm{XRD}$ and scanning electron microscope (SEM) analyses were performed on magnetic extract coming from FB28 and FB34b samples in order to confirm the presence of magnetite and greigite (Figure 8). SEM 
A

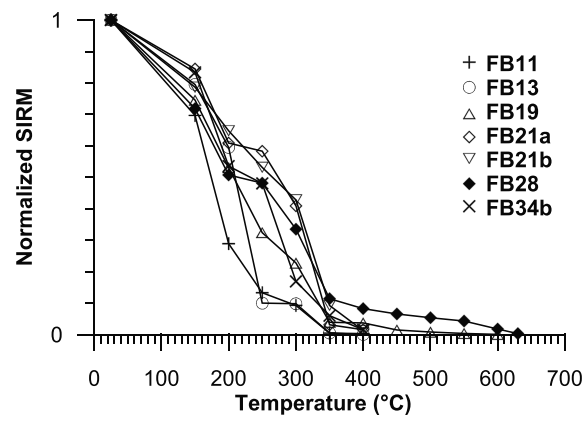

B

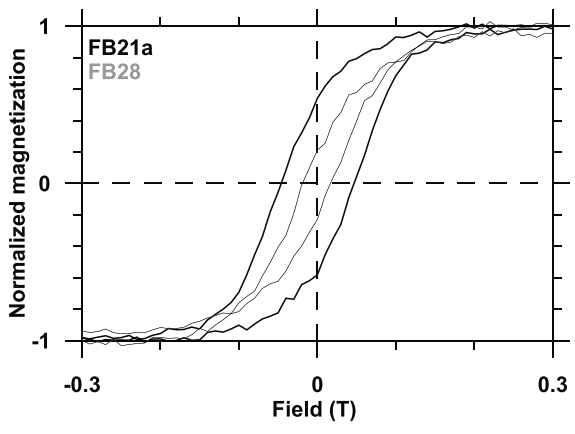

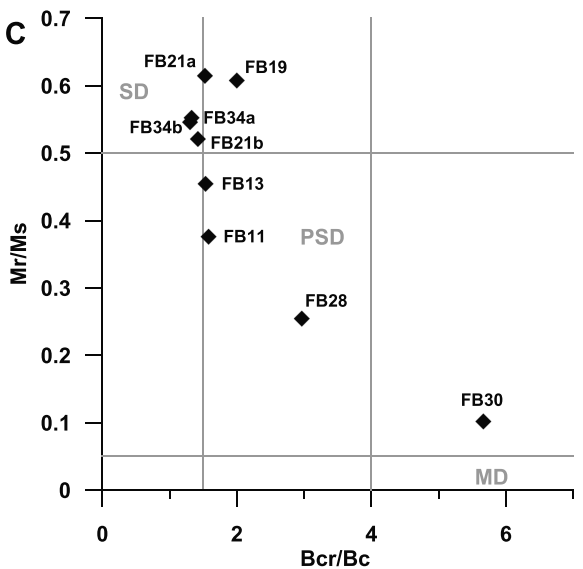

Figure 7. (a) IRM versus temperature for seven discrete samples showing a strong loss of magnetization between 200 and $350^{\circ} \mathrm{C}$. Two samples are characterized by a loss of the remaining signal at around $600^{\circ} \mathrm{C}$. (b) Two representative hysteresis loops. (c) Ratios of hysteresis and backfield parameters: remanent magnetization $\left(M_{r}\right)$, saturation magnetization $\left(M_{S}\right)$, coercive field of remanence $\left(B_{\mathrm{cr}}\right)$, and coercive field $\left(B_{c}\right)$, plotted on Day diagram with single domain, pseudo-single domain, and multidomain area for titanomagnetites (Day et al., 1977).

(EDAX PhiZAF) observations were performed using partial vacuum and backscattered mode on nonmetallized samples and X-ray diffractometry was performed using a Philips PW3710 equipped with a cobalt anode ( $\lambda=1.79 \AA$, measuring step of $0.025^{\circ}$, counting time of $10 \mathrm{~s}$ for FB2 8 and $9 \mathrm{~s}$ for FB34b). Characteristic peaks of magnetite $\left(2.53 \AA, 41.40^{\circ}\right)$ are identified in Fb28, whereas greigite $\left(2.98 \AA, 34.93^{\circ}\right)$ and mackinawite $\left(5.03 \AA, 36.93^{\circ}\right)$ - a nonmagnetic iron sulfide-are identified in FB34b. Siderite $(2.82 \AA$, $34.93^{\circ}$ ), an authigenic mineral often associated with greigite (e.g., Sagnotti et al., 2005), was also detected
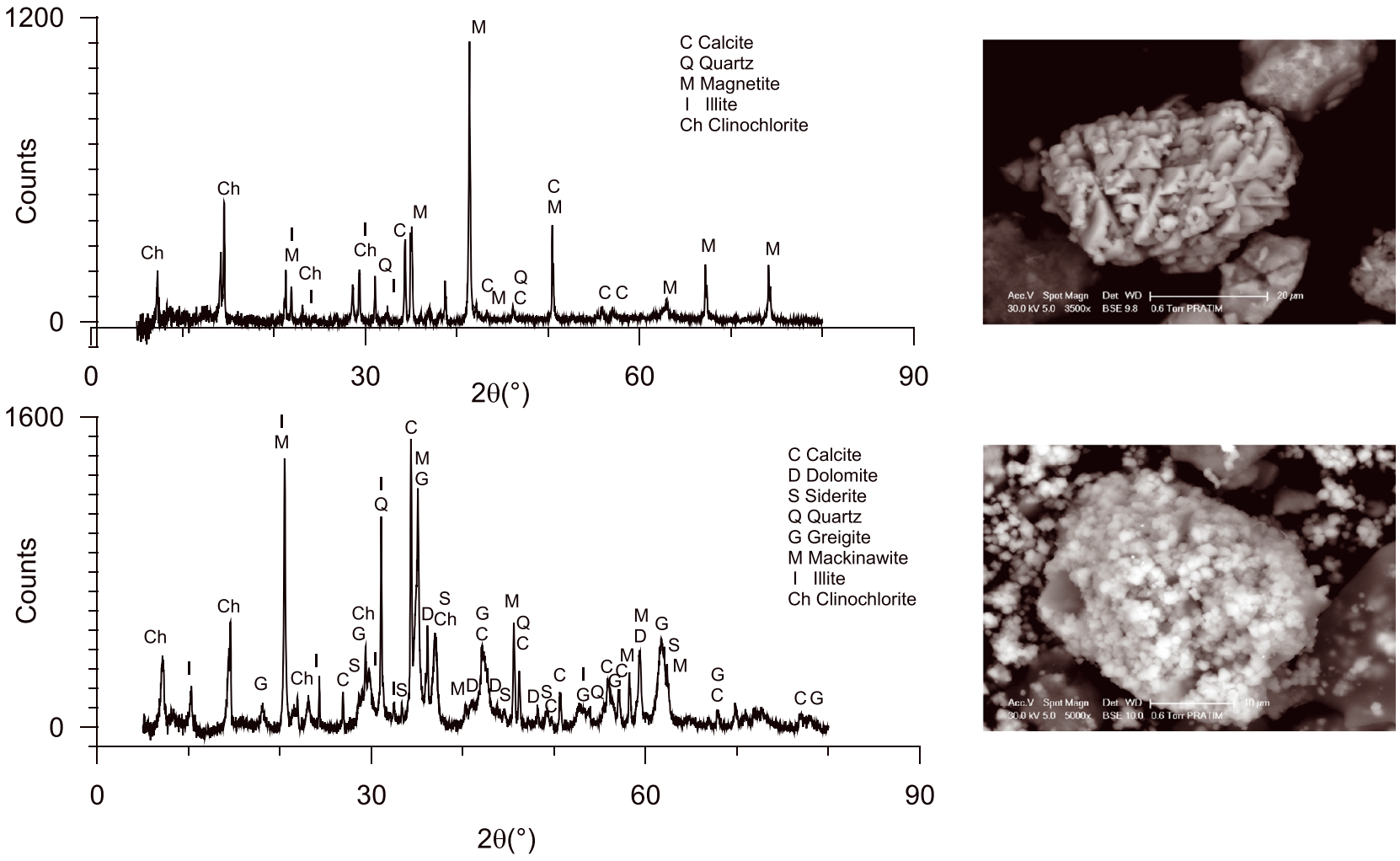

Figure 8. XRD and SEM results for magnetic extract of (top) FB28 and (bottom) FB34b. XRD patterns and SEM images show predominance of magnetite in FB28 and predominance of greigite in FB34b. 


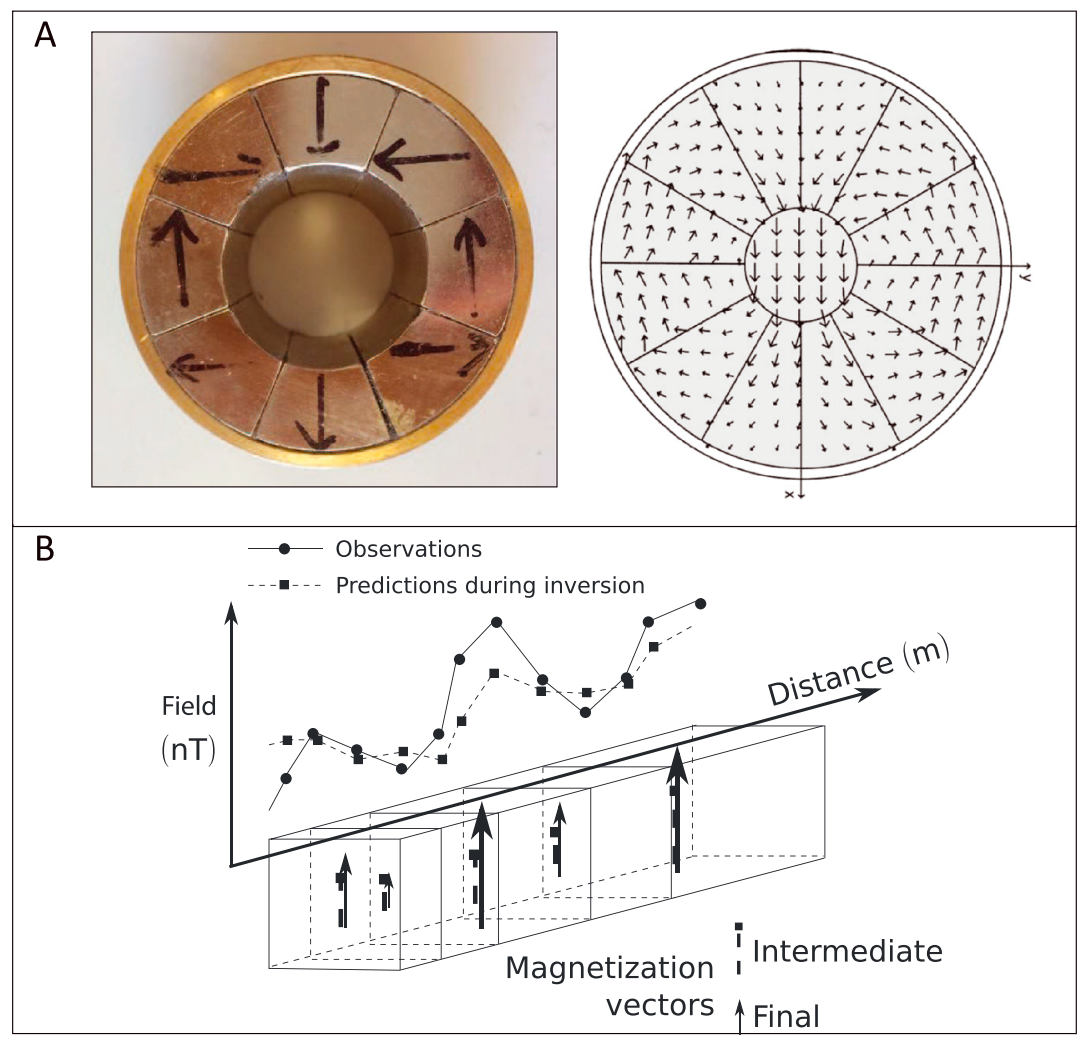

Figure 9. Workflow applied to the three selected U-channels: (a, left) Halbach (eight magnets, inner diameter of $35 \mathrm{~mm}$ and length of $50 \mathrm{~mm}$ ) cylinder used in the present study. (a, right) Modeled magnetic field map in the Halbach (12 magnets, inner diameter of $28 \mathrm{~mm}$ and length of $60 \mathrm{~mm}$ ) cylinder (Rochette et al., 2001) showing the homogeneity in the passthrough hole. (b) Modelization scheme to interpret magnetic fields in prism magnetization.

in FB34b sample. SEM analyses confirm the presence of aggregates of well-formed octahedral crystals of magnetite and aggregates of micrometer-sized cubic crystals of greigite.

Element dispersion spectroscopy shows that the magnetite observed in FB28 sample is enriched in $\mathrm{Ti}$ and $\mathrm{Cr}$, pointing toward detrital origin for this magnetic mineral. Magnetic analyses supported by SEM and XRD indicate that greigite is the only carrier of the magnetic signal in FB11, FB13, FB21a, FB21b, FB34, and FB34b samples. The magnetization of greigite being $59 \mathrm{Am}^{2} / \mathrm{kg}$ (Chang et al., 2008) we can deduce that the percentage of greigite in the measured samples ranges from 0.01 to $0.36 \%$.

\subsection{Workflow}

Three 1.5-m-long U-channels representative of the whole unaltered sequence were retrieved from the sediment cores at different depth (Figure 6). Prior to the scanning, U-channels were passed through a Halbach cylinder (Figure 9a) in order to produce an IRM perpendicular to the long axis of the U-channel and parallel to the fluxgate probe. The intensity of the magnetic field produced by the Halbach cylinder used is $0.6 \mathrm{~T}$, a magnetic field strong enough to saturate sediments according to the magnetic mineralogy. It has to be noticed that Halbach cylinders suffers from magnetic deflections at their borders (Rochette et al., 2001). In the present study, the most external sediments of U-channel passing through the "eight-magnet" Halbach cylinder suffer of a maximum deflection of $29^{\circ}$. By comparing magnetic scanning of samples subject to Halbach and pulse magnetization procedures, it turns out that the effect of the deflection produces a maximum discrepancy of $20 \mathrm{nT}$ in the steepest signal transition that is negligible regarding the noise level and the positioning error (see Figure S2).

Once the magnetization is acquired, the magnetic field produced by the magnetized U-channel was scanned with steps every $\sim 500 \mu \mathrm{m}$ (Figure 2a). The magnetic field can be used as a rough estimate of relative 


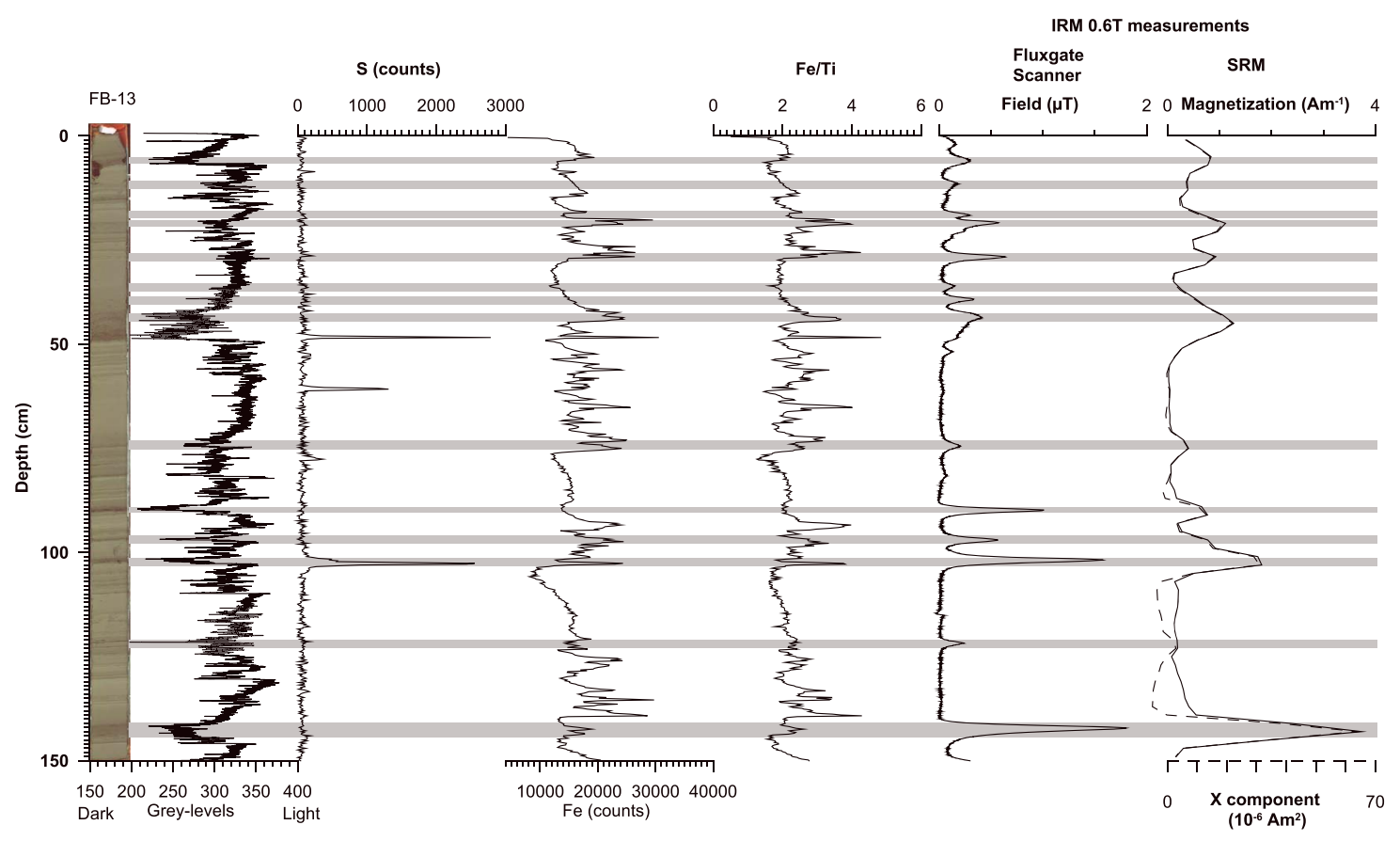

Figure 10. Photography and gray levels of half-split core, $\mathrm{S}, \mathrm{Fe}$, and Fe/Ti from XRF, magnetic field measured by fluxgate scanning and magnetic intensity, and $X$ component measured with the Superconducting Rock Magnetometer for the IRM 0.6 T acquired on the U-channel of core section FB13. Magnetic field enhancements are highlighted in gray: they more likely fit the darkest layers than the Fe increases.

concentration in magnetic minerals within the sediment. For a more quantitative approach, a modeling based on uniformly magnetized prisms is performed hereafter (Figure $9 \mathrm{~b}$ and section 5.5).

\subsection{Comparison of the Magnetic Field Variation With XRF, Gray Levels, and Low-Resolution Remanent Magnetization}

Figure 10 compares the high-resolution magnetic field scanning, gray levels determined from color images, XRF data (both acquired with the ITRAX system), and remanent magnetization determined with the Superconducting Rock Magnetometer (model 760R, 2G Enterprises) on section FB13. Gray levels were determined from color images using the Image Processing Toolbox from MatLab and are expressed in arbitrary units (AU) with values varying from 200 to $370 \mathrm{AU}$. XRF was performed at 2-mm resolution using an Xray fluorescence core scanner (ITRAX, Cox Analytical Systems) with a chromium X-ray source (45 kV, 30 $\mathrm{mA}$ ) and a 20-s counting time.

The comparison between $X$ component (direction of the expected maximum magnetization) and magnetization in SRM measurements (Figure 10) shows that the magnetic signal is mostly unidirectional. Nevertheless, some tilts in the signal orientation exist in U-channel FB13 but they are restricted to very low magnetization intervals, that is, in interval where the magnetic field is not detected by the fluxgate scanner. Therefore, these tilts of the magnetic signal do not affect the interpretation of the magnetic field scanning. No significant tilt in the magnetic signal is observed in the other sedimentary sections (Figure 11).

Comparing magnetic field scanning with IRM measurement using SRM, magnetic field variation ranges from 0 to $2 \mu \mathrm{T}$ for a magnetization ranging from 0 to $4 \mathrm{Am}$ for U-channel FB13 (Figure 10). These ranges of variation are coherent with results from U-channel FB19 and FB32 which show maximum magnetization values of 2.5 and $2 \mathrm{Am}$ for magnetic fields of 1.2 and $0.8 \mu \mathrm{T}$, respectively (Figure 11). Due to the higher spatial resolution, the intervals marked by a magnetic increase are narrower for the magnetic field record than for the SRM magnetization record.

The comparison of magnetic field variation with gray levels and XRF results show that most of magnetic field increases are observed in the darkest layers (highlighted by gray lines in Figures 10 and 11). Nevertheless, the magnetic increase is sometimes restricted in an interval thinner than the dark level like 

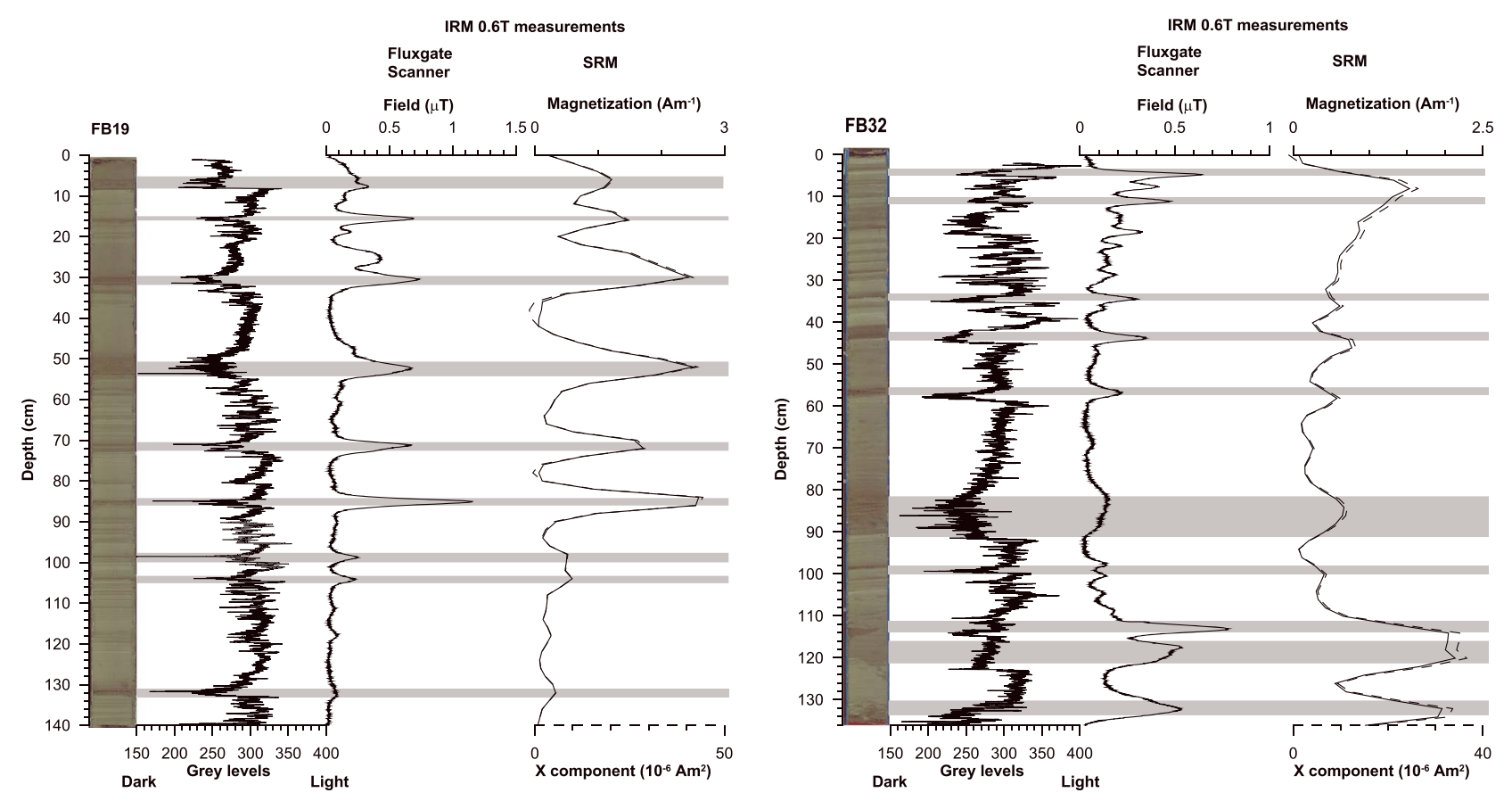

Figure 11. Photography and gray levels of half-split cores, magnetic field from fluxgate scanning and magnetic intensity, and $X$ component measured with the Superconducting Rock Magnetometer for the IRM 0.6T acquired on U-channels for cores (left) FB19 and (right) FB32. Increases in magnetic field are highlighted in gray.

between 40 and $50 \mathrm{~cm}$ in U-channel FB13 for instance (Figure 10). Apart from some exceptions, this correlation is a general feature throughout the sedimentary sequence.

Correlation of magnetic field with XRF values is more difficult to define. Indeed, increases in sulfur, which should be linked to mineralization of highly magnetic greigite, mostly do not correlate with magnetic field peaks, except at $110 \mathrm{~cm}$ in U-channel FB13 (Figure 10). This misfit could be either due to oxidation of greigite or to its heterogeneous distribution in a single layer. Fe and Fe/Ti records show similarities which could be attributed to Fe mobility in the pore water linked postdepositional redox processes (e.g., Demory et al., 2005). Some peaks of Fe/Ti correlate with magnetic field increases in U-channel FB13 (Figure 10) at 20, $30,44,75,98$, and $103 \mathrm{~cm}$. Nevertheless, other intervals do not fit like at 90 and at $140 \mathrm{~cm}$.

The comparison between magnetic field variation, magnetization, gray level, and XRF data show that modeling is needed in order to estimate the thickness and magnetization intensity of layers responsible for magnetic field variations.

\subsection{Modeling the Sedimentary Record}

Three discretization approaches were applied to model the magnetization variations in the studied sediment. First, an inversion using a sequence of uniformly magnetized prisms with a constant thickness was conducted. Theoretically, setting the smallest constant thickness (e.g., $1 \mathrm{~mm}$ ) would give the best result to fit the magnetic field data. However, it numerically costs time and it leads to unrealistically high magnetization values ( $>1,000 \mathrm{Am}$ ). If we select a thickness on the order of the signal integration (about $14 \mathrm{~mm}$ ), the RMS residuals are too large, especially for the strongest anomalies. Therefore, after several tests, $5 \mathrm{~mm}$ as standard thickness for all prisms was found to be the best compromise, fitting data, converging fast (few minutes for 300 prisms after scanning a $1.5-\mathrm{m}$ core section) and leading to coherent modeled magnetization values for sedimentary sections. The results are shown in Figure 12a. The 773-nT RMS residual value is due to imperfect fitting of the peak of some intense and sharp anomalies (like at 900 and 1,000 $\mathrm{mm}$ of Z-distance). This incomplete fitting is due to the sample-sensor distance estimated at $10.6 \mathrm{~mm}$, which may not be the best value for some magnetized layers in the core (see Figure $5 \mathrm{~b}$ and section 4 of this manuscript for a discussion on this point). About five prisms have magnetization intensities higher than $10 \mathrm{Am}$. 


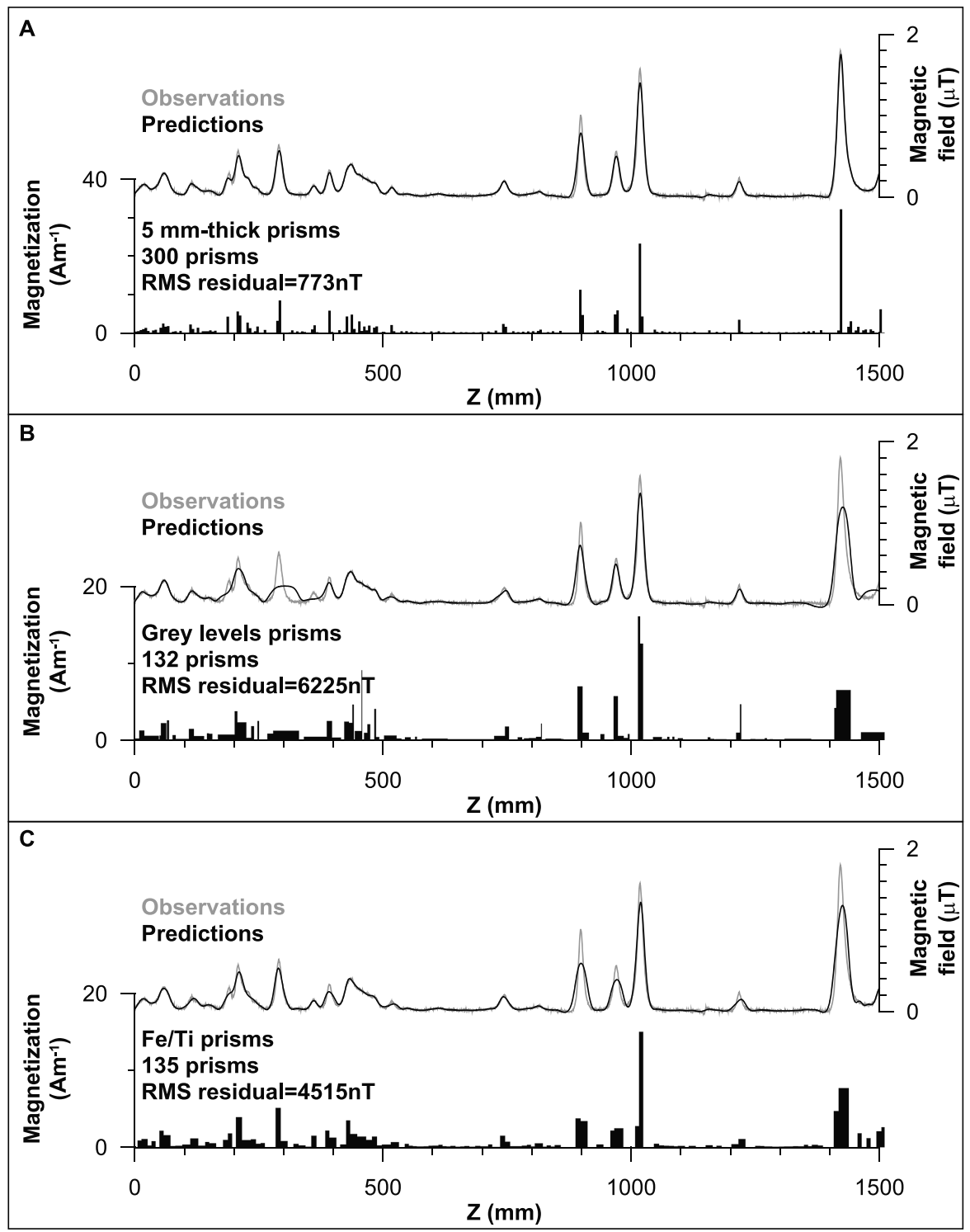

Figure 12. Modeling based on successive prisms with their magnetization, magnetic field prediction, and magnetic field observation. (a) Modeling based on the succession of 5-mm-thick prisms. (b) Modeling based on prisms of various thicknesses determined from gray level transitions. (c) Modeling based on prisms of various thicknesses determined from $\mathrm{Fe} / \mathrm{Ti}$ from XRF measurements.

In a second procedure, the discretization of the core section was based on the gray level records. Those records were smoothed using a sliding window, and the gradient was computed using second-order accurate central differences in the interior points and either first- or second-order accurate one-sided (forward or backward) differences at boundaries. Using this technique, it turns out that the number of prisms determined with gray level data is 132, that is, less half of the number using 5-mm constant thickness. The inversion of the magnetic field data using this configuration of "gray level prisms" (Figure 12b) gives a best model with large RMS residuals (6,225 nT), in comparison to the " 5 -mm thickness" approach. Around 1,420 mm of Z-distance, the gray level prism fails to fit the corresponding large magnetic field anomaly of about $2 \mu \mathrm{T}$. The same failure is observed nearby $300 \mathrm{~mm}$ of Z-distance. This probably means that those sedimentary intervals are not magnetically homogeneous. On the other hand, at about 1,220 mm of $Z$ distance, a thin (3 mm) 5-Am gray level prism succeeds in fitting the corresponding 200-nT anomaly, similarly to the corresponding 5-mmthick 2-Am prism of the constant thickness model (Figure 12a). This shows that-sometimes-the 5-mm thickness could be reduced to better simulate the magnetic field signal. 
A third mode of inversion was performed (Figure 12c), now using XRF data to constrain the thickness of the prisms. Better results than in the "gray level configuration" are obtained (RMS residual of 4,515 nT), but still this is far from the quality of the model using a constant 5-mm thickness. In details, the left side (top) of the U-channel seems to be well defined by this XRF discretization, but not on the right side of the section, where the "XRF prisms" seem to be too large to fit the corresponding magnetic field anomalies.

Therefore, the modeling based on constant and small thickness prisms gives the best description of the magnetic field variation. Comparison with sediment description and XRF-based models evidences intervals in which diagenesis and/or sedimentary facies may influence the magnetic signal. The fact that some magnetized prisms do not correspond to any features detected in the other proxies also unveils that the magnetic "scanning" approach is very powerful to decipher sedimentary issues. Another very important outcome from the modeling is the estimate of the intensity of magnetization. Indeed, whatever the modeling approach chosen in terms of prisms definition, the estimated magnetizations are much higher and restricted to some intervals (Figure 12) than with measurements using Superconducting Rock Magnetometer (Figures 10 and 11), which present low-amplitude and low-frequency variations due to low spatial resolution. Using our modeling approach, it turns out that magnetic record is more likely due to small size prisms with magnetization up to 20 Am than large prisms with magnetization reaching 2 to $4 \mathrm{Am}$ as shown by SRM measurements. Still the estimation of local magnetizations from measurements using either SRM or our fluxgate device strongly depends on the volume integration of each magnetic field data set itself. In order to solve the convolution problem due to volume integration, Oda and Shibuya (1996) proposed a statistical approach based on Akaike's Bayesian information criterion minimization. The algorithm was improved by incorporating new parameters to account for errors in sample measurement position and length and tested on 200 repeated measurements of a U-channel sample (Oda \& Xuan, 2014; Xuan \& Oda, 2015). In the present study, the convolution of the magnetic field signal is minimized by the increased spatial resolution making a modeling approach based on a succession of uniformly magnetized thin prisms more optimal. In addition, the modeling of data acquired with the magnetic field scanner helps to estimate more realistic magnetizations because the scanner configuration optimizes the spatial resolution and the modeling calibration is adapted to the measured sedimentary section.

\section{Conclusions}

Our fully automated magnetic scanner has shown its ability to produce rapid and high spatial resolution measurements of the magnetic field locally generated by sediment magnetization at the contact of Uchannels. We have also shown that the scanner offers a magnetic parameter with spatial resolution (14 $\mathrm{mm}$ ) approaching resolution of other high-resolution proxies. The spatial resolution can even be increased by fluxgate scanning of fine continuous samples (such as millimeter-thick rock slices). In this case, spatial resolution may reach $5.8 \mathrm{~mm}$.

In the case study of the Cassis paleolake sediments, the comparison of results from the magnetic scanner with the gray levels and XRF results helped to constrain the process responsible for the magnetic concentration variation and mineral assemblage. The modeling approach based either on constant size prisms or prisms determined from gray levels and XRF allows the discrimination between sedimentary facies and diagenesis that influence the magnetic signal differently from a sedimentary interval to another. The high spatial resolution magnetic scanner coupled with a robust modeling approach offers therefore a powerful tool in sedimentology. Our approach shows that a much more in-depth interpretation of the remanence fluctuations versus gray level and XRF data would be desirable. This will be the subject of a forthcoming work, making use also of the organic matter signal.

Beyond this specific equipment dedicated to U-channel which can be easily upsized for larger sections (e.g., half cores), the choice of equipment to measure discrete samples or continuous sections of rocks has to be considered. A balance has to be found between sensitivity and spatial resolution depending on the type of measurement, the thickness of the continuous sample and the scientific question to be answered. Indeed, recent developments show the importance of adapting the equipment to the studied object (Uehara et al., 2017). 


\section{Acknowledgments}

This research was supported by two projects (magnetic scanner development and study of the Cassis paleolake) funded by ECCOREV federation and benefited from a PhD scholarship funded by the Conseil Regional PACA and FEDER fund, with the support of the Parc National des Calanques. We also thank Marine Segui and Arslane Amri for their help in probe calibration. S. Marguerite from SETEL/CEREGE and L. Augustin from C2FN INSU are acknowledged for operating the Cassis drilling. We acknowledge the altruism of several private landowners who repeatedly let us work in their fields and vineyards during sediment coring, as well as the help of the Cassis municipality. We finally would like to thank three anonymous reviewers for their contribution to improve the quality of the manuscript. The magnetic scanner and associated modeling led to the filing of patents (FR.16/53142 and PCT/EP2017/058 489). All the data used are listed in the references and archived at https://doi.pangaea.de/ 10.1594/PANGAEA.900447.
Future measurements with our equipment may concern segments of laminated hard rocks (e.g., banded iron formations) with oblique bedding. In addition, tests could be done with segments of breccia. In both cases, the modeling approach will require adapted geometries and configurations of the magnetized volumes.

\section{References}

Branch, M. A., Coleman, T. F., \& Li, Y. (1999). A subspace, interior, and conjugate gradient method for large-scale bound-constrained minimization problems. SIAM Journal on Scientific Computing, 21(1), 1-23. https://doi.org/10.1137/S1064827595289108

Chang, L., Roberts, A. P., Tang, Y., Rainford, B. D., Muxworthy, A. R., \& Chen, Q. (2008). Fundamental magnetic parameters from pure synthetic greigite $\left(\mathrm{Fe}_{3} \mathrm{~S}_{4}\right)$. Journal of Geophysical Research, 113(B6), B06104. https://doi.org/10.1029/2007JB005502

Dadson, R., Fuller, M., \& Pilant, W. (1974). On the measurement of the remanent magnetism of long cores. Geophysical Research Letters, 1(4), 185-188. https://doi.org/10.1029/GL001i004p00185

Day, R., Fuller, M., \& Schmidt, V. A. (1977). Hysteresis properties of titanomagnetites: Grain size and composition dependence. Physics of the Earth and Planetary Interiors, 13(4), 260-267. https://doi.org/10.1016/0031-9201(77)90108-X

Demory, F., Oberhänsli, H., Nowaczyk, N. R., Gottschalk, M., Wirth, R., \& Naumann, R. (2005). Detrital input and early diagenesis in sediments from Lake Baikal revealed by rock magnetism. Global and Planetary Change, 46(1-4), 145-166. https://doi.org/10.1016/j. gloplacha.2004.11.010

Dunlop, D. J., \& Özdemir, Ö. (1997). Rock magnetism: Fundamentals and frontiers. Cambridge: Cambridge University Press. https://doi. org/10.1017/CBO9780511612794

Glenn, D. R., Fu, R. R., Kehayias, P., Le Sage, D., Lima, E. A., Weiss, B. P., \& Walsworth, R. L. (2017). Micrometer-scale magnetic imaging of geological samples using a quantum diamond microscope. Geochemistry, Geophysics, Geosystems, 18, 3254-3267. https://doi.org/ 10.1002/2017GC006946

Hankard, F., Gattacceca, J., Fermon, C., Pannetier-Lecoeur, M., Langlais, B., Quesnel, Y., et al. (2009). Magnetic field microscopy of rock samples using a giant magnetoresistance-based scanning magnetometer. Geochemistry, Geophysics, Geosystems, 10, Q10Y06. https://doi. org/10.1029/2009GC002750

Hauser, M. W. (1991). Principles of oversampling A/D conversion. Journal of the Audio Engineering Society, 39, 3-26.

Lima, E. A., Bruno, A. C., Carvalho, H. R., \& Weiss, B. P. (2014). Scanning magnetic tunnel junction microscope for high-resolution imaging of remanent magnetization fields. IOP Measurement Science and Technology, 25(10), 105401. https://doi.org/10.1088/09570233/25/10/105401

Marshall, M., Schlolaut, G., Nakagawa, T., Lamb, H., Brauer, A., Staff, R., et al. (2012). A novel approach to varve counting using $\mu$ XRF and X-radiography in combination with thin-section microscopy, applied to the Late Glacial chronology from Lake Suigetsu, Japan. Quaternary Geochronology, 13, 70-80. https://doi.org/10.1016/j.quageo.2012.06.002

Oda, H., \& Shibuya, H. (1996). Deconvolution of long-core paleomagnetic data of Ocean Drilling Program by Akaike's Bayesian information criterion minimization. Journal of Geophysical Research, 101(B2), 2815-2834. https://doi.org/10.1029/95JB02811

Oda, H., \& Xuan, C. (2014). Deconvolution of continuous paleomagnetic data from pass-through magnetometer: A new algorithm to restore geomagnetic and environmental information based on realistic optimization. Geochemistry, Geophysics, Geosystems, 15, 3907-3924. https://doi.org/10.1002/2014GC005513

Plouff, D. (1976). Gravity and magnetic fields of polygonal prisms and application to magnetic terrain corrections. Geophysics, 41(4), 727-741. https://doi.org/10.1190/1.1440645

Quesnel, Y., Langlais, B., Sotin, C., \& Galdéano, A. (2008). Modeling and inversion of local magnetic. Journal of Geophysics and Engineering, 5(4), 387-400. https://doi.org/10.1088/1742-2132/5/4/003

Roberts, A. P. (1995). Magnetic properties of sedimentary greigite $\left(\mathrm{Fe}_{3} \mathrm{~S}_{4}\right)$. Earth and Planetary Science Letters, 134(3-4), 227-236. https:// doi.org/10.1016/0012-821X(95)00131-U

Roberts, A. P., Chang, L., Rowan, C. J., Horng, C. S., \& Florindo, F. (2011). Magnetic properties of sedimentary greigite (Fe $\left.\mathrm{S}_{4}\right)$ : An update. Reviews of Geophysics, 49, RG1002. https://doi.org/10.1029/2010RG000336

Rochette, P., Vadeboin, F., \& Clochard, L. (2001). Rock magnetic applications of Halbach cylinders. Physics of the Earth and Planetary Interiors, 126(1-2), 109-117. https://doi.org/10.1016/S0031-9201(01)00247-3

Romey, C., Rochette, P., Vella, C., Arfib, B., Andrieu-Ponel, V., Braucher, R., et al. (2014). Geophysical and geomorphological investigations of a Quaternary karstic paleolake and its underground marine connection in Cassis (Bestouan, Cassis, SE France). Geomorphology, 214, 402-415. https://doi.org/10.1016/j.geomorph.2014.02.021

Rothwell, R. G., \& Croudace, I. W. (2015). Twenty years of XRF core scanning marine sediments: What do geochemical proxies tell us? In I. W. Croudace, \& R. G. Rothwell (Eds.), Micro-XRF studies of sediment cores: Applications of a non-destructive tool for the environmental sciences, (Chap. 2, 25-102). Dordrecht, The Netherlands: Springer. https://doi.org/10.1007/978-94-017-9849-5_2

Sagnotti, L., Roberts, A. P., Weaver, R., Verosub, K. L., Florindo, F., Pike, C. R., et al. (2005). Apparent magnetic polarity reversals due to remagnetization resulting from late diagenetic growth of greigite from siderite. Geophysical Journal International, 160, 89-100. https:// doi.org/10.1111/j.1365-246X.2005.02485.X

Shaw, G., Kramer, R. B., Dempsey, N. M., \& Hasselbach, K. (2016). A scanning Hall-probe microscope for high resolution, large area, variable height magnetic field imaging. Review of Scientific Instruments, 87, 113702. https://doi.org/10.1063/1.4967235

Uehara, M., Gattacceca, J., Quesnel, Y., Lepaulard, C., Lima, E. A., Manfredi, M., \& Rochette, P. (2017). A spinner magnetometer for large Apollo lunar samples. Review of Scientific Instruments, 88(10), 104502. https://doi.org/10.1063/1.5008905

Uehara, M., \& Nakamura, N. (2007). Scanning magnetic microscope system utilizing a magneto-impedance sensor for a nondestructive diagnostic tool of geological samples. Review of Scientific Instruments, 78(4), 043708. https://doi.org/10.1063/1.2722402

Uehara, M., van der Beek, C. J., Gattacceca, J., Skidanov, V. A., \& Quesnel, Y. (2010). Advances in magneto-optical imaging applied to rock magnetism and paleomagnetism. Geochemistry, Geophysics, Geosystems, 11, Q05Y09. https://doi.org/10.1029/2009GC002653

Weiss, B. P., Lima, E. A., Fong, L. E., \& Baudenbacher, F. J. (2007). Paleomagnetic analysis using SQUID microscopy. Journal of Geophysical Research, 112(B9), B09105. https://doi.org/10.1029/2007JB004940

Xuan, C., \& Oda, H. (2015). UDECON: Deconvolution optimization software for restoring high-resolution records from pass-through paleomagnetic measurements. Earth, Planets and Space, 67(1). https://doi.org/10.1186/s40623-015-0332-x 